\title{
Role of Parenting Style in Children's Behavioral Problems through the Transition from Preschool to Elementary School According to Gender in Japan
}

\author{
Rikuya Hosokawa 1,2,*(D) and Toshiki Katsura ${ }^{2}$ \\ 1 School of Nursing, Nagoya City University, Nagoya 467-8601, Japan \\ 2 Graduate School of Medicine, Kyoto University, Kyoto 606-8501, Japan; tkatsura@hs.med.kyoto-u.ac.jp \\ * Correspondence: rikuya@med.nagoya-cu.ac.jp; Tel.: +81-52-853-8058
}

Received: 28 August 2018; Accepted: 17 December 2018; Published: 21 December 2018

check for updates

\begin{abstract}
While ineffective discipline can be attributed to authoritarian and permissive parenting styles, little research has examined the role of gender in the association between parenting style and early childhood behavioral problems. Thus, this study aimed to clarify the effects of authoritarian and permissive parenting on children's externalizing and internalizing behaviors during the preschool-to-elementary-school transition according to gender in Japan. A sample of 1668 Japanese children (853 boys and 815 girls) were followed longitudinally over one-year intervals, and assessed based on parenting styles (the Parenting Scale), children's behavioral problems (the Strengths and Difficulties Questionnaire), and family characteristics. Multivariate analyses revealed that, when analyzed by gender, authoritarian discipline influenced externalizing problems in boys ( $\beta=0.048$, $p=0.047)$ and girls $(\beta=0.067, p=0.023)$, while permissive discipline influenced externalizing problems in boys only $(\beta=0.049, p=0.038)$. The results document the relationship between family processes and the development of disruptive behavior disorders in children. Support for parents employing such child-rearing styles in early childhood may be effective in reducing school maladjustment.
\end{abstract}

Keywords: authoritarian parenting; permissive parenting; internalizing problem; externalizing problem; gender; preschool children

\section{Introduction}

Behavioral problems including externalizing problems (e.g., hyperactivity, rule-breaking behaviors, and aggression) and internalizing problems (e.g., anxiety, withdrawal, and depression) are among the most common mental health issues in early childhood [1-3]. Moreover, behavioral problems in early childhood are a significant predictor of negative mental health outcomes in later life [4-6]. For example, they are highly predictive of a range of difficulties during childhood, such as conduct disorder, poor scholastic achievement, and peer rejection [7-9], as well as negative outcomes in adolescence and adulthood, such as mental health problems, poor employment prospects, and antisocial behavior [10-12]. During early childhood, several developmental trajectories emerge [13,14]. Behavioral problems in early childhood may also hinder the development of a range of social, emotional, and cognitive competences in children $[15,16]$, and early childhood is a critical period for the development of behavioral problems related to social maladaptation. Finally, untreated behavioral problems during early childhood are considered disadvantageous [17-19]. Thus, to prevent the development of behavioral problems, it is necessary to understand the early childhood development of these problems as well as their etiology and developmental course.

Early childhood child-rearing environments can significantly affect the incidence of children's behavioral problems. The family is a social arrangement that exerts significant influence on children's 
development and parenting styles, and in particular, influences the social environments of children within the family. Moreover, parenting is an ecological variable that significantly influences a child's personality development [20-22]. Some previous studies have suggested that maternal and paternal parenting styles play a central role in understanding the development of externalizing and internalizing behaviors $[23,24]$, since parenting style exacerbates or reduces children's behavioral problems [25-27]. The effects on development of parenting behaviors in childhood tend to be stable over time $[28,29]$. Depending on the parenting style they adopt, parents elect to use different discipline strategies to manage their children's behavior and such strategies are considered a fundamental aspect of parenting [30].

The most frequent categorization of ineffective discipline includes the two styles of parenting identified by Baumrind - the authoritarian and permissive styles-each of which is theorized to differentially influence offspring [31-33]. According to Baumrind's typology, parenting styles vary on a two-dimensional framework of parental demandingness (e.g., control, supervision, maturity demands), which refers to the role parents play in promoting respect for rules and social conventions, and responsiveness (e.g., warmth, acceptance, involvement), which is related to the level of parental involvement between children and parents. Ineffective discipline can be attributed to two parental authority prototypes or styles, authoritarian and permissive, which are characterized as being either high or low on the two parenting dimensions (i.e., demandingness and responsiveness).

The authoritarian style has high demandingness and low responsiveness and is characterized by firmly enforced rules and edicts decided by parents as well as strong control over children's autonomy [34-37]. Parents with an authoritarian style attempt to control the behavior of their children in accordance with a set standard of conduct, usually an absolute standard [33]. Authoritarian parents tend to use demands to discipline their children and only allow them minimal autonomy. They also demonstrate low affection and emotional warmth in their parent-child relationships $[36,37]$. This type of parenting is likely to be negatively associated with children's psychosocial development; that is, children of authoritarian parents are likely to have low self-esteem, be less content and less secure, and have negative attitudes toward the world; conversely, they are likely to do well in terms of obedience to standards $[37,38]$.

Permissive parenting, on the other hand, has low demands and high responsiveness. It is characterized by a lack of monitoring, control, and discipline, yet it is warm and nurturing [39,40]. Permissive parents attempt to behave in a nonpunitive and accepting manner toward their children's desires and actions and allow their children to regulate their own activities as much as possible [33]. Permissive parenting occurs when parents fail to set limits and do not expect developmentally appropriate behavior of their children. As a consequence, this type of parenting is likely to be negatively associated with children's psychosocial development and children of permissive parents exhibit characteristics such as narcissistic tendencies, social irresponsibility, and self-centered motivation [41,42]. Consequently, both authoritarian and permissive disciplinary styles are potentially harmful for children's psychosocial development. Furthermore, such parental styles have been linked consistently with a variety of negative developmental outcomes including behavioral problems over time [43-49].

Although several studies focusing on parenting styles and behavioral problems and involving mixed samples (i.e., including both boys and girls) have linked ineffective discipline to disruptive behavioral problems in children, these studies did not differentiate between boys and girls. That is, the research has not sufficiently examined how parenting styles influence child outcomes within the context of child gender dyads. Children's gender has been found to be important in the emergence of child behavior problems and how children respond to parenting styles, and several studies have suggested the role of gender differences in internalizing versus externalizing problems [50-56]. Early childhood is a critical period for child development related to social adaptation. Because gender can play a role in discipline-associated outcomes in early childhood, it is important to clarify the effects of authoritarian and permissive parenting on behavioral problems according to gender in this period. Furthermore, there is consistent evidence with mixed samples in North American and European 
families that authoritarian and permissive parenting in early childhood are associated with poor child outcomes. Although it has been debated whether these relationships can be generalized to families in East Asian cultures, several studies using East Asian subjects have produced similar results to those using Western subjects. For instance, concerning school performance, one study focusing on Chinese children (mean age 7 years) demonstrated a negative effect of authoritarian parenting [57]. Another study on Chinese children (mean age 9 years) demonstrated that authoritarian parenting led to low self-regulation and learning problems in children [58]. However, while many studies have shown the cultural differences between East Asian and Western parenting styles, there has been limited research on the effect of authoritarian and permissive parenting on behavioral problems in early childhood in Japan. Japanese and Chinese parents are more likely to endorse an authoritarian parenting style, such as strictness and parental control, than parents from Western cultures $[59,60]$. Moreover, children in East Asian countries are more likely to be required to be obedient and polite than those in Western countries $[61,62]$. Thus, cultural differences can play a role in discipline-associated child outcomes in early childhood and it is important to clarify the effects of authoritarian and permissive parenting on behavioral problems according to gender in early childhood in Japan.

In summary, authoritarian and permissive parenting directly impact children's behavioral problems. Although many studies have focused on this relationship, to date, not enough research has examined the association between parenting style and children's behavioral problems in early childhood, with a focus on the role of child gender. In Japan specifically, limited research has examined the effect of authoritarian and permissive parenting style in early childhood on behavioral problems. Therefore, the present study attempts to clarify the effects of authoritarian and permissive parenting respectively in early childhood on the externalizing and internalizing problem behaviors of children in elementary school, focusing on gender, in Japanese children. The influence of different negative parenting styles in preschool on the presence of externalizing and internalizing problem behaviors in elementary school could differ between boys and girls. We hypothesized that in a mixed sample using Japanese subjects, authoritarian and permissive parenting in early childhood would be associated with poor child outcomes, producing similar results to studies conducted in other countries. We also hypothesized that authoritarian parenting would be more strongly associated with behavioral problems in girls than in boys and that permissive parenting would be more strongly associated with behavioral problems in boys than in girls.

\section{Materials and Methods}

\subsection{Participants}

The children targeted by this study, all of whom were five years old, were recruited from 52 kindergartens and 78 nursery schools. Recruitment was conducted in 2014 in Nagoya City, which is a major urban area in Aichi Prefecture in Japan. The targeted children and their parents participated in the longitudinal project designed to examine the influence of family factors on children's social developmental outcomes. The first two cohorts (2014: T1; 2015: T2) of participants were included in this study. A total of 3314 of the 5024 target families completed the baseline assessment (T1), and of these, 1787 completed both the baseline (T1) and follow-up assessments (T2), indicating a retention rate of $53.9 \%$.

To recruit participants, self-report questionnaires were distributed to all parents of the targeted children $(n=5024)$ at $\mathrm{T} 1$ when the children were five years old and in preschool, and the response rate was $66.0 \%(n=3314)$. At $\mathrm{T} 2$, when the children were six years old and in first grade, a second questionnaire was distributed to the families $(n=3314)$ and the response rate was $53.9 \%(n=1787)$. Thus, the attrition rate from $\mathrm{T} 1$ to $\mathrm{T} 2$ was $46.1 \%$, with $44.7 \%$ not responding at $\mathrm{T} 2$ and $1.4 \%(n=46)$ having relocated.

There were a number of significant differences between those who participated in the baseline and one-year follow-up assessments $(n=1787)$ and those who did not respond to the T2 assessments 
( $n=1527)$, with the latter being more likely to have lower socioeconomic status (SES) (i.e., lower household income and parents with lower levels of education). A comparison of the demographic features between the non-returning and returning participants revealed that $16.2 \%$ of the non-returning participants' annual household income was less than $¥ 3,000,000$, while this was true of only $10.0 \%$ of the returning participants; the household income of the non-returning participants was significantly lower than that of the returning participants, as measured by a chi-square test. In addition, $5.8 \%$ of the non-returning participants' maternal educational background comprised compulsory education, while this was true of only $2.4 \%$ of the returning participants; furthermore, $7.6 \%$ of the non-returning participants' paternal educational background comprised compulsory education, while this was true of only $4.7 \%$ of the returning participants. Both the maternal and paternal educational levels of non-returning participants were significantly lower than those of the returning participants, as measured by a chi-square test. Thus, the non-returning participants tended to have relatively lower SES than did returning participants, meaning that there was a lower response rate of individuals with low SES compared to those with high SES. Hence, those participants lost from the sample comprised families with higher rates of lower sociodemographic factors, meaning that these families were underrepresented in our sample and our results may be less generalizable to families with a lower socioeconomic background.

To accurately clarify the associations between parenting attitude and child developmental outcomes, we then chose to exclude children with developmental problems $(n=75)$ and children whose mothers did not complete question items regarding parenting attitude and child developmental outcomes $(n=44)$. Consequently, of the 1787 children for whom data were received at both $\mathrm{T} 1$ and T2, $1668(93.3 \%)$ met the inclusion criteria.

\subsection{Ethics Statement}

The researchers obtained written, informed consent from all participants. Written, informed consent was obtained on behalf of the children from their parents. Ethical approval for this study was obtained from Kyoto University's Ethics Committee in Kyoto, Japan (E2322). All procedures performed in studies involving human participants were in accordance with the standards of the ethics committee.

\subsection{Measures}

\subsubsection{Parenting Behavior: Parenting Scale (PS)}

The Parenting Scale (PS) is a questionnaire that measures dysfunctional discipline styles in parents to manage children's behavior [63]. The PS Japanese version was used in this study [64]. At the baseline assessment, parents completed the PS. Each of the 30 items is rated on a 7-point scale. Two subscales from the PS were used to assess dysfunctional discipline practices when faced with problem situations. Ratings of parental behavior are obtained with regard to ineffective discipline styles: laxness (i.e., permissive discipline) and over-reactivity (i.e., authoritarian discipline). The scale shows adequate internal consistency and also correlates closely with direct observations of mother-child interactions $[63,64]$. The Cronbach's alphas for laxness and over-reactivity in this sample were 0.70 and 0.86 , respectively; the scale demonstrated adequate internal consistency (see Table 1).

For the PS Japanese version, the items of over-reactivity were similar to those of the original version [63]. Regarding laxness, although the concept was similar, slight differences were observed in the items. Specifically, although the original version included "If saying 'No' doesn't work, I offer my child something nice so he/she will behave" as one of the laxness items, the Japanese version did not include this item and instead included "When my child pesters me, I can't ignore the pestering." In Japanese, "laxness" is likely to mean that parents are at their children's beck and call rather than that parents make a deal with children to temporarily handle the situation. Thus, adjustments to the PS were made to account for the difference between Japanese and Western permissive parenting styles. 
Table 1. Descriptive statistics for the study variables $(n=1668)$.

\begin{tabular}{ccccc}
\hline Description & Range & Mean & SD & $\alpha$ \\
\hline Parenting practices: Parenting Scale (PS) & & & & \\
Laxness & $1-7$ & 2.53 & 0.78 & 0.70 \\
Over-reactivity & $1-7$ & 3.62 & 1.10 & 0.86 \\
\hline Child adjustment: Strengths and Difficulties Questionnaire (SDQ) & & & & \\
Internalizing problems at preschool & $0-20$ & 3.26 & 2.63 & 0.65 \\
Externalizing problems at preschool & $0-20$ & 4.98 & 3.19 & 0.74 \\
Internalizing problems at first grade & $0-20$ & 3.81 & 3.00 & 0.71 \\
Externalizing problems at first grade & $0-20$ & 5.13 & 3.30 & 0.77 \\
\hline
\end{tabular}

Abbreviations: Standard Deviation (SD); Cronbach's Alpha $(\alpha)$.

\subsubsection{Child Behavioral Problems: The Strengths and Difficulties Questionnaire (SDQ)}

The Strengths and Difficulties Questionnaire (SDQ) measures child behavioral problems [65]. The SDQ Japanese version was used in this study [66]. Parents completed the SDQ at both the baseline assessment (T1) and at the one-year follow-up assessment (T2). The SDQ is a 25-item measure of parents' perceptions of prosocial and difficult behaviors in their children, designed to assess the frequency of positive and negative behaviors in children [65]. It comprises five subscales (i.e., emotional symptoms, conduct problems, hyperactivity, peer problems, and prosocial behavior), and the score for each subscale is computed by adding the scores for the five items. The difficult behavior score in the SDQ is calculated as the sum of the scores obtained on the emotional symptoms, conduct problems, hyperactivity, and peer problems subscales. In this study, the emotional symptoms and peer problems subscales of the SDQ were combined to form an internalizing problems scale, while the conduct problems and hyperactivity-inattention subscales were combined to form an externalizing problem scale, as suggested by Goodman et al. [67]. The scale has been validated as having adequate internal reliability [66]. In this sample, the Cronbach's alphas for internalizing and externalizing problems were $0.65-0.71$ and $0.74-0.77$, respectively; the scale demonstrated adequate internal consistency (see Table 1).

\subsubsection{Demographic Covariates}

Parents provided their demographic information, including child's sex, family structure (single-parent or two-parent family), attending institution (kindergarten or nursery school), annual household income, maternal education level, and paternal education level. Regarding family income, parents reported their annual household income in Japanese yen (JPY). In this study, the median household income was between 5.00 and 5.99 million JPY, and the average number of people per household was 4.3. In Japan, the median income of a four-person household is approximately 6.00 million JPY, so the household income of participants in this study was relatively similar to the typical Japanese distribution. The threshold for four-person households in Japan, calculated based on the Organisation for Economic Co-operation and Development's standard for the poverty line (i.e., half the median income of the total population), is an annual income of approximately 3.00 million JPY [68]. Therefore, with reference to those values, we created four categories of income: $<3$ million, 3-5 million, 6-8 million, and $\geq 9$ million JPY. Regarding parental education, both parents were asked to report their education in years, as well as the highest level of education completed. The Japanese education system comprises elementary school (6 years), junior high school (3 years), and high school ( 3 years), and education is compulsory until the end of junior high school ( 9 years). Based on the data, we created four categories of education level: compulsory education (9 years), upper secondary school (12 years), up to four years of college/university (13-15 years), and four or more years of college/university ( $\geq 16$ years). At the baseline assessment, parents provided complete information regarding these factors (see Table 2). 
Table 2. Participant characteristics at preschool (T1).

\begin{tabular}{|c|c|c|c|c|c|c|}
\hline \multirow{2}{*}{ Participant Characteristics } & \multicolumn{2}{|c|}{ Total $(n=1668)$} & \multicolumn{2}{|c|}{ Boys $(n=853)$} & \multicolumn{2}{|c|}{ Girls $(n=815)$} \\
\hline & $n$ & $\%$ & $n$ & $\%$ & $n$ & $\%$ \\
\hline \multicolumn{7}{|l|}{ Family structure } \\
\hline Single-parent family & 105 & 6.3 & 60 & 7.0 & 45 & 5.5 \\
\hline Two-parent family & 1563 & 93.7 & 793 & 93.0 & 770 & 94.5 \\
\hline \multicolumn{7}{|l|}{ Attending institution } \\
\hline Nursery school & 883 & 52.9 & 451 & 52.9 & 432 & 53.0 \\
\hline Kindergarten & 785 & 47.1 & 402 & 47.1 & 383 & 47.0 \\
\hline \multicolumn{7}{|l|}{ Annual household income (in millions of JPY) } \\
\hline$<3$ & 165 & 10.2 & 97 & 11.7 & 68 & 8.6 \\
\hline $3-5$ & 711 & 43.8 & 365 & 44.0 & 346 & 43.5 \\
\hline $6-8$ & 467 & 28.7 & 225 & 27.1 & 242 & 30.4 \\
\hline$\geq 9$ & 282 & 17.4 & 143 & 17.2 & 139 & 17.5 \\
\hline \multicolumn{7}{|l|}{ Maternal education level } \\
\hline Compulsory education & 41 & 2.5 & 19 & 2.2 & 22 & 2.7 \\
\hline Upper secondary school & 400 & 24.2 & 208 & 24.6 & 192 & 23.8 \\
\hline Up to four years at college/university & 671 & 40.6 & 355 & 42.0 & 316 & 39.2 \\
\hline More than four years at college/university & 540 & 32.7 & 264 & 31.2 & 276 & 34.2 \\
\hline \multicolumn{7}{|l|}{ Paternal education level } \\
\hline Compulsory education & 80 & 5.0 & 40 & 5.0 & 40 & 5.1 \\
\hline Upper secondary school & 386 & 24.2 & 193 & 24.0 & 193 & 24.5 \\
\hline Up to four years at college/university & 236 & 14.8 & 131 & 16.3 & 105 & 13.3 \\
\hline More than four years at college/university & 891 & 55.9 & 441 & 54.8 & 450 & 57.1 \\
\hline
\end{tabular}

Abbreviations: Japanese Yen (JPY).

\subsection{Data Analyses}

First, the relationships between participant characteristics and children's behavioral problems were analyzed via $t$-test or one-way analysis of variance (ANOVA) as shown in Table 3. Second, the effects of parenting practices during preschool (T1) on children's outcomes in first grade (T2) were assessed using multiple linear regression, with PS scores of laxness (i.e., permissive discipline) and over-reactivity (i.e., authoritarian discipline) as predictors and SDQ scores of internalizing or externalizing problems as the outcome (see Tables 4-6). Table 4 shows the entire sample of both boys and girls $(n=1668)$, Table 5 shows only boys $(n=853)$, and Table 6 shows only girls $(n=$ 815). Multivariate regression analyses were performed as follows: in Models 1-2, each predictor was entered individually to assess its univariate association with each outcome (i.e., laxness (Model 1), over-reactivity (Model 2)). In Model 3, both predictors (i.e., laxness and over-reactivity) were entered simultaneously. As several participant characteristics at T1 were significantly associated with behavioral problems at $\mathrm{T} 1$ in the analyses (see Table 3), we included the factors as covariates in each analysis (see Tables 4-6). Multicollinearity among the predictors was assessed, and no problems were found. IBM SPSS Statistics 23.0 (IBM Corporation, New York, NY, USA) was used for all statistical analyses with a significance level of $5 \%$. 
Table 3. Participant characteristics at preschool (T1) and behavioral problems in first grade (T2).

\begin{tabular}{|c|c|c|c|c|c|c|c|c|c|c|c|c|c|c|c|c|c|c|}
\hline \multirow{3}{*}{ Participant Characteristics } & \multicolumn{6}{|c|}{ Total } & \multicolumn{6}{|c|}{ Boys } & \multicolumn{6}{|c|}{ Girls } \\
\hline & \multicolumn{3}{|c|}{ Internalizing Problems } & \multicolumn{3}{|c|}{ Externalizing Problems } & \multicolumn{3}{|c|}{ Internalizing Problems } & \multicolumn{3}{|c|}{ Externalizing Problems } & \multicolumn{3}{|c|}{ Internalizing Problems } & \multicolumn{3}{|c|}{ Externalizing Problems } \\
\hline & Mean & SD & $p$ & Mean & SD & $p$ & Mean & SD & $p$ & Mean & SD & $p$ & Mean & SD & $p$ & Mean & SD & $p$ \\
\hline \multicolumn{19}{|l|}{ Sex } \\
\hline Boys & 3.78 & 2.96 & 0.612 & 5.7 & 3.42 & $<0.001^{* * *}$ & - & - & - & - & - & - & - & - & - & - & - & - \\
\hline Girls & 3.85 & 3.04 & & 4.50 & 3.05 & & - & - & & - & - & & - & - & & - & - & \\
\hline \multicolumn{19}{|l|}{ Family structure } \\
\hline Single-parent family & 4.31 & 3.33 & $0.044^{*}$ & 6.18 & 4.02 & $0.006 * *$ & 3.95 & 3.23 & 0.646 & 6.41 & 3.98 & 0.176 & 4.78 & 3.42 & 0.036 * & 5.89 & 4.09 & $0.022 *$ \\
\hline Two-parent family & 3.78 & 2.98 & & 5.06 & 3.24 & & 3.77 & 2.94 & & 5.68 & 3.37 & & 3.80 & 3.01 & & 4.42 & 2.96 & \\
\hline \multicolumn{19}{|l|}{ Attending institution } \\
\hline Nursery school & 3.94 & 2.99 & $0.048 *$ & 5.35 & 3.38 & $0.004 * *$ & 3.91 & 2.95 & 0.169 & 5.96 & 3.47 & 0.039 * & 3.97 & 3.04 & 0.228 & 4.71 & 3.16 & $0.036^{*}$ \\
\hline Kindergarten & 3.67 & 3.00 & & 4.88 & 3.20 & & 3.63 & 2.97 & & 5.47 & 3.35 & & 3.72 & 3.04 & & 4.26 & 2.90 & \\
\hline \multicolumn{19}{|l|}{ Annual household income (in millions of JPY) } \\
\hline$<3$ & 4.59 & 3.41 & $<0.001^{* * *}$ & 5.85 & 3.58 & $<0.001^{* * *}$ & 4.79 & 3.29 & 0.006 ** & 6.18 & 3.51 & 0.135 & 4.30 & 3.58 & $0.002 * *$ & 5.40 & 3.65 & $<0.001^{* * *}$ \\
\hline 3-5 & 3.96 & 2.99 & & 5.31 & 3.25 & & 3.72 & 2.88 & & 5.82 & 3.30 & & 4.22 & 3.09 & & 4.78 & 3.10 & \\
\hline $6-8$ & 3.55 & 2.87 & & 4.99 & 3.16 & & 3.62 & 2.85 & & 5.67 & 3.38 & & 3.50 & 2.90 & & 4.36 & 2.79 & \\
\hline$\geq 9$ & 3.46 & 2.95 & & 4.37 & 3.21 & & 3.60 & 3.13 & & 5.19 & 3.54 & & 3.30 & 2.75 & & 3.52 & 2.59 & \\
\hline \multicolumn{19}{|l|}{ Maternal education level } \\
\hline Compulsory education & 5.44 & 3.80 & $<0.001^{* * *}$ & 7.00 & 3.98 & $<0.001^{* * *}$ & 5.56 & 3.84 & 0.002 ** & 7.67 & 4.24 & $<0.001 * * *$ & 5.34 & 3.86 & $<0.001^{* * *}$ & 6.45 & 3.76 & $0.001^{* *}$ \\
\hline Upper secondary & 4.20 & 3.01 & & 5.65 & 3.37 & & 3.84 & 2.76 & & 6.39 & 3.34 & & 4.58 & 3.21 & & 4.85 & 3.23 & \\
\hline Up to four years at college/university & 3.87 & 2.97 & & 5.10 & 3.27 & & 4.02 & 3.04 & & 5.68 & 3.33 & & 3.70 & 2.89 & & 4.46 & 3.07 & \\
\hline More than four years at college/university & 3.32 & 2.84 & & 4.62 & 3.11 & & 3.32 & 2.90 & & 5.12 & 3.38 & & 3.32 & 2.80 & & 4.13 & 2.75 & \\
\hline \multicolumn{19}{|l|}{ Paternal education level } \\
\hline Compulsory education & 4.58 & 3.59 & 0.040 * & 5.91 & 3.54 & $<0.001 * * *$ & 4.53 & 3.04 & 0.448 & 6.53 & 3.52 & $<0.001 * * *$ & 4.63 & 4.10 & 0.215 & 5.30 & 3.50 & 0.079 \\
\hline Upper secondary school & 3.93 & 3.07 & & 5.56 & 3.36 & & 3.74 & 3.09 & & 6.49 & 3.42 & & 3.74 & 2.99 & & 4.63 & 3.03 & \\
\hline Up to four years at college/university & 3.74 & 3.04 & & 5.35 & 3.29 & & 3.78 & 3.01 & & 5.94 & 3.37 & & 4.11 & 3.15 & & 4.62 & 3.04 & \\
\hline More than four years at college/university & 3.72 & 2.89 & & 4.71 & 3.13 & & 3.73 & 2.90 & & 5.21 & 3.29 & & 3.71 & 2.89 & & 4.23 & 2.89 & \\
\hline
\end{tabular}

Abbreviations: Standard Deviation (SD); $p$-value $(p)$; ${ }^{*}$ significance at $p<0.05 ;{ }^{* *}$ significance at $p<0.01 ;{ }^{* * *}$ significance at $p<0.001$. 
Table 4. Effect of parenting practices at preschool (T1) on behavioral problems at first grade (T2) in both boys and girls.

\begin{tabular}{|c|c|c|c|c|c|c|c|c|c|c|c|c|}
\hline \multirow{2}{*}{ Parenting Practices } & \multicolumn{4}{|c|}{$\begin{array}{l}\text { Model } 1 \\
\text { Laxness }\end{array}$} & \multicolumn{4}{|c|}{$\begin{array}{c}\text { Model } 2 \\
\text { Over-Reactivity }\end{array}$} & \multicolumn{4}{|c|}{$\begin{array}{c}\text { Model } 3 \\
\text { Laxness and Over-Reactivity }\end{array}$} \\
\hline & B & SE & $\beta$ & $p$ & B & SE & $\beta$ & $p$ & B & SE & $\beta$ & $p$ \\
\hline \multicolumn{13}{|l|}{ Internalizing Problems } \\
\hline Laxness & 0.144 & 0.081 & 0.037 & 0.075 & - & - & - & - & 0.133 & 0.082 & 0.034 & 0.107 \\
\hline Over-reactivity & - & - & - & - & 0.111 & 0.057 & 0.040 & 0.052 & 0.095 & 0.058 & 0.035 & 0.102 \\
\hline Adjusted $\mathrm{R}^{2}$ & \multicolumn{4}{|c|}{0.363} & \multicolumn{4}{|c|}{0.370} & \multicolumn{4}{|c|}{0.369} \\
\hline \multicolumn{13}{|l|}{ Externalizing Problems } \\
\hline Laxness & 0.193 & 0.078 & 0.046 & $0.013^{*}$ & - & - & - & - & 0.168 & 0.079 & 0.040 & 0.034 * \\
\hline Over-reactivity & - & - & - & - & 0.178 & 0.057 & 0.060 & $0.002^{* *}$ & 0.164 & 0.058 & 0.055 & $0.005^{* *}$ \\
\hline Adjusted $\mathrm{R}^{2}$ & \multicolumn{4}{|c|}{0.493} & \multicolumn{4}{|c|}{0.496} & \multicolumn{4}{|c|}{0.498} \\
\hline
\end{tabular}

Note: Internalizing problems: Controlled for sex, family structure, attending institution, annual household income, maternal education level, paternal education level, and T1 internalizing problems. Externalizing problems: Controlled for sex, family structure, attending institution, annual household income, maternal education level, paternal education level, and T1 externalizing problems. Abbreviations: Unstandardized coefficient (B); Standard Error (SE); Standardized coefficient ( $\beta) ; p$-value $(p) ;{ }^{*}$ significance at $p<0.05 ;{ }^{* *}$ significance at $p<0.01$.

Table 5. Effect of parenting practices at preschool (T1) on behavioral problems at first grade (T2) boys only.

\begin{tabular}{|c|c|c|c|c|c|c|c|c|c|c|c|c|}
\hline \multirow{2}{*}{ Parenting Practices } & \multicolumn{4}{|c|}{$\begin{array}{l}\text { Model } 1 \\
\text { Laxness }\end{array}$} & \multicolumn{4}{|c|}{$\begin{array}{c}\text { Model } 2 \\
\text { Over-Reactivity }\end{array}$} & \multicolumn{4}{|c|}{$\begin{array}{c}\text { Model } 3 \\
\text { Laxness and Over-Reactivity }\end{array}$} \\
\hline & B & SE & $\beta$ & $p$ & B & SE & $\beta$ & $p$ & B & SE & $\beta$ & $p$ \\
\hline \multicolumn{13}{|l|}{ Internalizing Problems } \\
\hline Laxness & 0.177 & 0.113 & 0.046 & 0.111 & - & - & - & - & 0.182 & 0.115 & 0.047 & 0.112 \\
\hline Over-reactivity & - & - & - & - & 0.106 & 0.081 & 0.038 & 0.192 & 0.088 & 0.082 & 0.032 & 0.285 \\
\hline Adjusted $\mathrm{R}^{2}$ & \multicolumn{4}{|c|}{0.369} & \multicolumn{4}{|c|}{0.375} & \multicolumn{4}{|c|}{0.380} \\
\hline \multicolumn{13}{|l|}{ Externalizing Problems } \\
\hline Laxness & 0.244 & 0.113 & 0.055 & $0.028 *$ & - & - & - & - & 0.218 & 0.115 & 0.049 & $0.038^{* *}$ \\
\hline Over-reactivity & - & - & - & - & 0.170 & 0.085 & 0.054 & $0.042 *$ & 0.153 & 0.086 & 0.048 & $0.047^{* *}$ \\
\hline Adjusted $\mathrm{R}^{2}$ & \multicolumn{4}{|c|}{0.504} & \multicolumn{4}{|c|}{0.505} & \multicolumn{4}{|c|}{0.507} \\
\hline
\end{tabular}

Note: Internalizing problems: Controlled for family structure, attending institution, annual household income, maternal education level, paternal education level, and T1 internalizing problems. Externalizing problems: Controlled for family structure, attending institution, annual household income, maternal education level, paternal education level, and T1 externalizing problems. Abbreviations: Unstandardized coefficient (B); Standard Error (SE); Standardized coefficient $(\beta) ; p$-value $(p) ;{ }^{*}$ significance at $p<0.05$; ${ }^{* *}$ significance at $p<0.01$.

Table 6. Effect of parenting practices at preschool (T1) on behavioral problems at first grade (T2) girls only.

\begin{tabular}{|c|c|c|c|c|c|c|c|c|c|c|c|c|}
\hline \multirow{2}{*}{ Parenting Practices } & \multicolumn{4}{|c|}{$\begin{array}{l}\text { Model } 1 \\
\text { Laxness }\end{array}$} & \multicolumn{4}{|c|}{$\begin{array}{c}\text { Model } 2 \\
\text { Over-Reactivity }\end{array}$} & \multicolumn{4}{|c|}{$\begin{array}{c}\text { Model } 3 \\
\text { Laxness and Over-Reactivity }\end{array}$} \\
\hline & B & SE & $\beta$ & $p$ & B & SE & $\beta$ & $p$ & B & SE & $\beta$ & $p$ \\
\hline \multicolumn{13}{|l|}{ Internalizing Problems } \\
\hline Laxness & 0.119 & 0.117 & 0.030 & 0.308 & - & - & - & - & 0.088 & 0.119 & 0.022 & 0.460 \\
\hline Over-reactivity & - & - & - & - & 0.119 & 0.080 & 0.044 & 0.138 & 0.103 & 0.082 & 0.038 & 0.210 \\
\hline Adjusted $\mathrm{R}^{2}$ & \multicolumn{4}{|c|}{0.366} & \multicolumn{4}{|c|}{0.376} & \multicolumn{4}{|c|}{0.385} \\
\hline \multicolumn{13}{|l|}{ Externalizing Problems } \\
\hline Laxness & 0.142 & 0.108 & 0.037 & 0.183 & - & - & - & - & 0.117 & 0.109 & 0.031 & 0.282 \\
\hline Over-reactivity & - & - & - & - & 0.188 & 0.076 & 0.071 & 0.014 * & 0.178 & 0.078 & 0.067 & $0.023 *$ \\
\hline Adjusted $\mathrm{R}^{2}$ & \multicolumn{4}{|c|}{0.456} & \multicolumn{4}{|c|}{0.464} & \multicolumn{4}{|c|}{0.474} \\
\hline
\end{tabular}

Note: Internalizing problems: Controlled for family structure, attending institution, annual household income, maternal education level, paternal education level, and T1 internalizing problems. Externalizing problems: Controlled for family structure, attending institution, annual household income, maternal education level, paternal education level, and T1 externalizing problems. Abbreviations: Unstandardized coefficient (B); Standard Error (SE); Standardized coefficient $(\beta) ; p$-value $(p)$; * significance at $p<0.05$. 


\section{Results}

\subsection{Study Population}

Participants' demographic characteristics at preschool (i.e., at baseline) are shown in Table 2, and the relationships between participants' demographic characteristics and emotional/behavioral problems at first grade are shown in Table 3. The children's average age was 6.09 years $(\mathrm{SD}=$ $0.30)$, with $51.1 \%$ boys $(n=853)$ and $48.9 \%$ girls $(n=815)$. Regarding family structure, in the mixed sample and girls sample, the internalizing problem scores of children from single-parent families were significantly higher than those of children from two-parent families; similarly, in the mixed sample and girls sample, externalizing problem scores of children from single-parent families were significantly higher than those of children from two-parent families. Regarding attending institution, in the mixed sample, nursery school children's internalizing problem scores were significantly higher than kindergarten children's internalizing problem scores; in the mixed sample, boys sample, and girls sample, nursery school children's externalizing problem scores were significantly higher than kindergarten children's externalizing problem scores. Regarding annual household income, in the mixed, boys, and girls samples, the internalizing problem scores of children from lower-income households were significantly higher than those of children from higher-income households; similarly, in the mixed, boys, and girls samples, the externalizing problem scores of children from lower-income households were significantly higher than those of children from higher-income households. Regarding maternal education level, in the mixed, boys, and girls samples, the internalizing problem scores of children from lower-income households were significantly higher than those of children from higher-income households; similarly, in the mixed, boys, and girls samples, the externalizing problem scores of children from lower-income households were significantly higher than those of children from higher-income households. Regarding paternal education level, in the mixed sample, the internalizing problem scores of children from lower-income households were significantly higher than those of children from higher-income households; in the mixed and boys samples, the externalizing problem scores of children from lower-income households were significantly higher than those of children from higher-income households.

\subsection{Effect of Parenting Practices on Behavioral Problems}

The associations between parenting practices and children's outcomes were assessed using multiple linear regression, with PS scores of laxness (i.e., permissive discipline) and over-reactivity (i.e., authoritarian discipline) as predictors and SDQ scores of internalizing or externalizing problems as the outcome (see Tables 4-6). First, regarding analysis targeting boys and girls $(n=1668)$, the results of the multivariate analysis between parenting practices and behavioral problems are shown in Table 4. Regarding internalizing problems as the outcome, in the models that included individual predictors (i.e., Models 1 and 2), each predictor (i.e., laxness and over-reactivity) was not significantly associated with internalizing problems. Further, in Model 3 (which contained both predictors), no predictor was significantly associated with internalizing problems. On the other hand, regarding externalizing problems as the outcome, in Models 1 and 2, each predictor was significantly associated with externalizing problems. Further, in Model 3, both laxness $(\beta=0.040, p=0.034)$ and over-reactivity $(\beta=0.055, p=0.005)$ were significantly associated with externalizing problems.

Second, regarding analysis targeting only boys $(n=853)$, the results of the multivariate analysis between parenting practices and behavioral problems are shown in Table 5. Regarding internalizing problems as the outcome, in Models 1 and 2, laxness and over-reactivity were not significantly associated with internalizing problems. Further, even in Model 3, these predictors were not significantly associated with internalizing problems. On the other hand, regarding externalizing problems as the outcome, in Models 1 and 2, each predictor was significantly associated with externalizing problems. Further, in Model 3, both laxness $(\beta=0.049, p=0.038)$ and over-reactivity $(\beta=0.048, p=0.047)$ were significantly associated with externalizing problems. 
Finally, regarding analysis targeting only girls $(n=815)$, the results of the multivariate analysis between parenting practices and behavioral problems are shown in Table 6. Regarding internalizing problems as the outcome, in Models 1 and 2, laxness and over-reactivity were not significantly associated with internalizing problems. Further, even in Model 3, both these predictors were not significantly associated with internalizing problems. On the other hand, regarding externalizing problems as the outcome, in Models 1 and 2, over-reactivity but not laxness was significantly associated with externalizing problems. Further, in Model 3, laxness was not significantly associated with externalizing problems, whereas over-reactivity was significantly associated with externalizing problems $(\beta=0.067, p=0.023)$.

\section{Discussion}

Based on our longitudinal observation, the findings of the present study highlighted the significant impact of parenting styles on children's behavioral problems, focusing on the role of child gender. Our results demonstrate a clear relationship between discipline styles in preschool for five-year-old children and behavioral problems in first grade for six-year-old children. These findings are consistent with previous studies that suggest that authoritarian and permissive disciplinary styles are associated with disruptive behavioral problems [69-73]. Specifically, multivariate analyses in the mixed sample revealed that not only higher over-reactivity (i.e., high authoritarian discipline) but also higher laxness (i.e., high permissive discipline) predicted clinically significant externalizing problems. In addition, based on an analysis of gender, authoritarian discipline was found to be related to externalizing problems in both boys and girls, whereas permissive discipline was related to externalizing problems only in boys. It is important to note that in our study, the relationships between parenting and child behavioral problems were found after controlling for child characteristics as well as demographic characteristics such as family structure and family SES at baseline. As these analyses controlled for these variables, the relationships between parenting and child behavioral problems were independent of the effect of child and demographic characteristics. Many studies have also suggested that behavior development identifies major risk factors for childhood behavioral problems; for example, not only parenting techniques but also child characteristics and family adversities such as low SES and single parenting have been shown to increase the risk of developing childhood behavioral difficulties [74-79]. A finding of note in the present study was gender difference that permissive discipline was related to externalizing behavioral problems for boys but not girls. Several of the mechanisms involved in this relationship between disciplinary styles and the risk of behavioral problems are likely to differ among boys and girls in early childhood.

\subsection{Effects of Authoritarian Parenting Style on Behavioral Problems}

The current findings suggest that the authoritarian parenting style was detrimental for both boys and girls. This finding is consistent with previous studies that also suggest that the authoritarian parenting style is linked to externalizing problems $[69,70,80-83]$. However, although most previous studies have analyzed mixed samples, they did not differentiate between boys and girls. This study, however, found that authoritarian discipline predicted clinically significant externalizing problems for both boys and girls. There was no gender difference in this relationship. Authoritarian discipline encompasses a restrictive style of interaction with children, which does not take the children's views and wishes into account. Authoritarian parents can influence the behaviors of their children in society, who tend to be unsuccessful because prohibition and power assertion are likely to be related to anxiety, fear, and frustration in children; moreover, such parents are likely to be subjected to their children's misbehaviors and other psychosocial behaviors. Indeed, children of parents with high-control parenting styles such as power-assertive, prohibitive, and punitive strategies have been shown to be less content, less secure, and more likely to become hostile or regressive and have greater difficulties dealing with somatic distress or psychological issues when under high stress than other children $[84,85]$. Moreover, coercive parenting styles are likely to prevent children from 
learning to self-regulate their own behaviors [86,87]. In addition, lack of parental warmth is also a risk factor for aggressive and disruptive behavioral problems in children [88] and could contribute to the development of deviant behaviors and adjustment problems. Therefore, in this study, children who received authoritarian parenting including high control and low warmth appear to be at an increased risk of externalizing behavioral problems.

Authoritarian parenting style tends to be more common in Japan than in Western countries [64], perhaps due to parents' expectations or environmental conditions. In Japan, children are required to be more obedient and polite than in Western countries [61]. For instance, when children make noise, parents may overreact from worry about bothering others. Therefore, parents in Japan may be more severe than Western parents in punishing bad behaviors and thus use a more control-oriented parenting style. Although we hypothesized that authoritarian parenting was more associated with behavioral problems in girls than in boys, we found that it was associated with behavioral problems in both boys and girls, perhaps influenced by the Japanese cultural background.

\subsection{Effects of Permissive Parenting Style on Behavioral Problems}

Permissive parenting was found to be related to disruptive behavior in boys but not in girls. Permissive parents dislike having control and authority over their children and therefore do not guide them to regulate their behaviors and allow them to make decisions alone. Because they are not comfortable imposing restrictions on their children, they tend to avoid and tolerate their children's misbehavior. This type of parenting style can allow the children to control their parents through coercion and thus indulges their low self-control and aggressive behaviors [41,42,89]. Consequently, it is assumed that the permissive parenting style will be positively associated with children's externalizing behavioral problems.

In this study, there was significant gender difference; permissive discipline was related to externalizing behavioral problems in boys but not in girls. Some sources suggest that non-permissive (i.e., firm) disciplinary strategies may be particularly important primarily for boys. For instance, the early parenting model for the development of disruptive behavior focuses primarily on boys and emphasizes the importance of non-permissive discipline to deal with disruptive behaviors [90,91]. The model focusing on gender in early intervention programs suggests that permissive discipline may be particularly detrimental for boys, perhaps because boys have less well-developed self-regulation processes than similarly aged girls $[92,93]$. This may also be attributed to the gender differences among children in accepting parenting style. How children rate fathers' or mothers' parenting styles may depend on the child's gender. A previous study suggested that boys perceived permissive parenting more than girls [94]. In addition, boys were likely to rate permissive styles less positively than girls [95]. These tendencies can more strongly influence the effect of permissive parenting on outcomes for boys than for girls. This study also found that respondents on parenting style were mothers. Boys, rather than girls, were more likely to rate mothers as permissive [94]. Thus, in this study, boys were more influenced by the permissive discipline of their mothers and in turn may be more exposed to the risk of behavioral problems from permissive parenting than girls. Therefore, in this study, there was likely to be gender difference; permissive discipline was related to externalizing behavioral problems in boys but not in girls.

On the other hand, as mentioned in the Materials and Methods section, although in the present study, the concept of laxness (i.e., permissive discipline) was similar in the PS Japanese version to the original version, slight differences were observed in the items. In Japanese, "laxness" is used to mean that parents are at their children's disposal rather than that parents negotiate with children to temporarily manage a given situation. Thus, the Japanese permissive parenting style may differ from Western countries' version thereof, meaning that this trend (i.e., permissive discipline's relation to externalizing behavioral problems in boys but not in girls) may differ in Western countries. 


\subsection{Limitations}

There are several limitations to this study, which need to be addressed in future research. First, this study was designed as an observational study. It is reasonable to assume that children's problem behaviors interact with parenting styles in predicting developmental outcomes. Many studies have reported that there are bidirectional relationships between children's conduct problems and negative parenting behaviors such as the use of harsh and coercive disciplinary strategies [70,96,97]. Negative parenting practices have often interacted with child oppositional and aggressive behavior, such that parents of children with behavioral problems were found to practice more negative parenting styles than parents of children without such problems [96,97]. Although this study included child behavioral problems as a baseline survey (T1) and a follow-up survey (T2), parenting style was only included in the baseline survey and therefore the transactional influence could not be estimated. Furthermore, although this study included child and family characteristics as moderator variables in the baseline survey to control for interaction effects, we did not include other multifaceted moderator variables. Therefore, further explorations should include parenting style in both the baseline and follow-up surveys and more multifaceted moderator variables or should conduct an intervention study.

Second, the present study did not include genetic factors. Child temperament has been conceptualized as a pathway through which children's genotypes affect parenting style because child temperament is genetically influenced [98]. For instance, children's negative emotionality was moderately associated with parental negativity and accounted for some part of the total child-based genetic contributions to parental negativity [99]. Further study should use a genetically informed design to include genetic factors; alternatively, twin studies could be conducted.

Third, in this study, to assess child behavioral problems, the SDQ was completed by parents only, which likely introduced reporting bias. Teachers' reports might be needed to evaluate this more accurately and further explorations should combine teacher as well as caregiver SDQ ratings. Furthermore, in this study, only mothers were asked about their parenting styles and the parenting styles of mothers and fathers are likely to differ. Apart from the fact that the quantity of time fathers and mothers spend with their children is different, there are indications that parental involvement is also qualitatively different; for instance, mothers were more likely to use an authoritative style, whereas fathers were more likely to use an authoritarian style [100,101]. In addition, children pick up parenting style differently from fathers and mothers; for instance, boys were more likely than girls to rate mothers as permissive and fathers as authoritarian, while girls tended to rate their mothers as more authoritative and fathers as more permissive [94]. Thus, the parenting styles of fathers and mothers are likely to differ, while boys and girls are likely to have different views on their mothers' and fathers' parenting styles. In future research, it is necessary to grasp the child-rearing styles of both fathers and mothers.

Finally, these findings may not be generalizable to all families due to a risk of attrition bias. The retention rate from $\mathrm{T} 1$ to $\mathrm{T} 2$ was $53.9 \%$, and the returning participants in $\mathrm{T} 2$ tended to have relatively higher SES than the non-returning participants, meaning that families with lower SES were underrepresented in our sample, and our results may be less generalizable to families with a lower socioeconomic background. This is a relatively universal problem in parenting research in general-parenting is sufficiently stressful that it is difficult to get the population of parents to participate. Future research would benefit from a study design using samples with higher retention rates (in particular, participants with lower SES).

\section{Conclusions}

This longitudinal study of a large sample of Japanese children found evidence that, during the important transition period between preschool and elementary school (age five to six), parenting style is associated with children's behavioral problems at age six. Authoritarian and permissive parenting styles are likely to continue to negatively influence children's development beyond childhood. In addition, authoritarian discipline was related to disruptive behaviors in both boys and girls, whereas 
permissive discipline was related to disruptive behaviors in boys but not in girls. The permissive parenting style will be associated positively with externalizing behavior in boys rather than girls because of gender deference. Few studies have examined the way parental authority influences the later development of behavioral problems in children, specifically with a focus on gender. These findings add to the substantial literature documenting the relationship between family processes and the development of disruptive behavior disorders in early childhood, specifically with a focus on gender. Therefore, support for parents that focuses on the negative effects of such child-rearing styles in early childhood according to child gender may be effective in preventing school maladjustment.

Author Contributions: R.H. designed the study, conducted the analyses, assisted with the literature review and discussion, and completed the journal revisions. T.K. contributed to the project administration and assisted with the review and editing of the manuscript.

Funding: This research was funded by JSPS KAKENHI Grant Number 26893224 and JSPS KAKENHI Grant Number 16K20858.

Acknowledgments: We gratefully acknowledge all the children, parents, and preschool teachers who participated in this study.

Conflicts of Interest: The authors declare no conflict of interest.

\section{References}

1. Gleason, M.M.; Goldson, E.; Yogman, M.W.; Council on Early Childhood; Committee on Psychosocial Aspects of Child and Family Health; Section on Developmental and Behavioral Pediatrics. Addressing early childhood emotional and behavioral problems. Pediatrics 2016, 138. [CrossRef]

2. Parry, T.S. Assessment of developmental learning and behavioural problems in children and young people. Med. J. Aust. 2005, 183, 43-48.

3. Egger, H.L.; Angold, A. Common emotional and behavioral disorders in preschool children: Presentation, nosology, and epidemiology. J. Child Psychol. Psychiatry 2006, 47, 313-337. [CrossRef]

4. Briggs-Gowan, M.J.; Carter, A.S. Social-emotional screening status in early childhood predicts elementary school outcomes. Pediatrics 2008, 121, 957-962. [CrossRef]

5. Calkins, S.D.; Blandon, A.Y.; Williford, A.P.; Keane, S.P. Biological, behavioral, and relational levels of resilience in the context of risk for early childhood behavior problems. Dev. Psychopathol. 2007, 19, 675-700. [CrossRef]

6. Kim-Cohen, J.; Arseneault, L.; Caspi, A.; Polo Tomás, M.; Taylor, A.; Moffitt, T.E. Validity of DSM-IV conduct disorder in 41/2-5-year-old children: A longitudinal epidemiological study. Am. J. Psychiatry 2005, 162, 1108-1117. [CrossRef]

7. Keane, S.P.; Calkins, S.D. Predicting kindergarten peer social status from toddler and preschool problem behavior. J. Abnorm. Child Psychol. 2004, 32, 409-423. [CrossRef]

8. Ladd, G.W.; Birch, S.H.; Buhs, E.S. Children's social and scholastic lives in kindergarten: Related spheres of influence? Child Dev. 1999, 70, 1373-1400. [CrossRef]

9. Reid, R.; Gonzalez, J.E.; Nordness, P.D.; Trout, A.; Epstein, M.H. A meta-analysis of the academic status of students with emotional/behavioral disturbance. J. Spec. Educ. 2004, 8, 130-143. [CrossRef]

10. Fergusson, D.M.; Boden, J.M.; Horwood, L.J. Classification of behavior disorders in adolescence: Scaling methods, predictive validity, and gender differences. J. Abnorm. Psychol. 2010, 119, 699-712. [CrossRef]

11. Leblanc, N.; Boivin, M.; Dionne, G.; Brendgen, M.; Vitaro, F.; Tremblay, R.E.; Pérusse, D. The development of Hyperactive-Impulsive behaviors during the preschool years: The predictive validity of parental assessments. J. Abnorm. Child Psychol. 2008, 36, 977-987. [CrossRef] [PubMed]

12. Rowe, R.; Costello, E.J.; Angold, A.; Copeland, W.E.; Maughan, B. Developmental pathways in oppositional defiant disorder and conduct disorder. J. Abnorm. Psychol. 2010, 119, 726-738. [CrossRef] [PubMed]

13. Denham, S.A. Social-emotional competence as support for school readiness: What is it and how do we assess it? Early Educ. Dev. 2006, 17, 57-89. [CrossRef]

14. Denham, S.A.; Blair, K.A.; DeMulder, E.; Levitas, J.; Sawyer, K.; Auerbach-Major, S. Preschool emotional competence: Pathway to social competence? Child Dev. 2003, 74, 238-256. [CrossRef] [PubMed] 
15. Nigg, J.T.; Huang-Pollock, C.L. An early onset model of the role of executive functions and intelligence in conduct disorder delinquency. In the Causes of Conduct Disorder and Serious Juvenile Delinquency; Lahey, B.B., Moffitt, T., Caspi, A., Eds.; Guilford Press: New York, NY, USA, 2003; pp. 227-253.

16. Wenar, C.; Kerig, P. Developmental Psychopathology: From Infancy Through Adolescence, 4th ed.; McGraw-Hill: Boston, MA, USA, 2000.

17. Granic, I.; Patterson, G.R. Toward a comprehensive model of antisocial development: A dynamic systems approach. Psychol. Rev. 2006, 113, 101-131. [CrossRef] [PubMed]

18. McKee, L.; Colletti, C.; Rakow, A.; Jones, D.J.; Forehand, R. Parenting and child externalizing behaviors: Are the associations specific or diffuse? Aggress. Violent Behav. 2008, 13, 201-215. [CrossRef] [PubMed]

19. Ferraro, K.F.; Schafer, M.H.; Wilkinson, L.R. Childhood disadvantage and health problems in middle and later life: Early imprints on physical health? Am. Sociol. Rev. 2016, 81, 107-133. [CrossRef]

20. Baumrind, D. Parental disciplinary patterns and social competence in children. Youth Soc. 1978, 9, $239-267$. [CrossRef]

21. Schaffer, M.; Clark, S.; Jeglic, E.L. The role of empathy and parenting style in the development of antisocial behaviors. Crime Delinq. 2009, 55, 586-599. [CrossRef]

22. Paulussen-Hoogeboom, M.C.; Stams, G.J.; Hermanns, J.M.; Peetsma, T.T.; van den Wittenboer, G. Parenting style as a mediator between children's negative emotionality and problematic behavior in early childhood. J. Genet. Psychol. 2008, 169, 209-226. [CrossRef] [PubMed]

23. Cummings, E.M.; Davies, P.T.; Campbell, S. Developmental Psychopathology and Family Processes; Guilford Press: New York, NY, USA, 2000.

24. Rinaldi, C.M.; Howe, N. Mothers' and fathers' parenting styles and associations with toddlers' externalizing, internalizing, and adaptive behaviors. Early Child Res. Q. 2012, 27, 266-273. [CrossRef]

25. Woolfson, L.; Grant, E. Authoritative parenting and parental stress in parents of pre-school and older children with developmental disabilities. Child Care Health Dev. 2006, 32, 177-184. [CrossRef] [PubMed]

26. Thomas, R.; Zimmer-Gembeck, M.J. Behavioral outcomes of parent-child interaction therapy and triple P-Positive parenting program: A review and meta-analysis. J. Abnorm. Child Psychol. 2007, 35, 475-495. [CrossRef]

27. Fujiwara, T.; Kato, N.; Sanders, M.R. Effectiveness of group positive parenting program (triple P) in changing child behavior, parenting style, and parental adjustment: An intervention study in japan. J. Child Fam. Stud. 2011, 20, 804-813. [CrossRef]

28. Sulik, M.J.; Blair, C.; Mills-Koonce, R.; Berry, D.; Greenberg, M.; Vernon-Feagans, L.; Burchinal, M.R.; Cox, M.; Garrett-Peters, P.T.; Frank, J.L.; et al. Early parenting and the development of externalizing behavior problems: Longitudinal mediation through children's executive function. Child Dev. 2015, 86, 1588-1603. [CrossRef]

29. van Dijk, R.; Dekovic, M.; Bunte, T.L.; Schoemaker, K.; Zondervan-Zwijnenburg, M.; Espy, K.A.; Matthys, W.C.H.J. Mother-child interactions and externalizing behavior problems in preschoolers over time: Inhibitory control as a mediator. J. Abnorm. Child Psychol. 2017, 45, 1503-1517. [CrossRef] [PubMed]

30. Laskey, B.J.; Cartwright-Hatton, S. Parental discipline behaviours and beliefs about their child: Associations with child internalizing and mediation relationships. Child Care Health Dev. 2009, 35, 717-727. [CrossRef] [PubMed]

31. Baumrind, D. Effects of authoritative control on child behavior. Child Dev. 1966, 37, 887-907. [CrossRef]

32. Baumrind, D. Child care practices anteceding three patterns of preschool behavior. Genet. Psychol. Monogr. 1967, 75, 43-88. [PubMed]

33. Baumrind, D. Current patterns of parental authority. Dev. Psychol. 1971, 4,1-103. [CrossRef]

34. Baumrind, D. Parenting: The discipline controversy revisited. Fam. Relat. 1996, 45, 405-414. [CrossRef]

35. Buehler, C.; Gerard, J.M. Marital conflict, ineffective parenting, and children's and adolescents' maladjustment. J. Marriage Fam. 2002, 64, 78-92. [CrossRef]

36. Winsler, A.; Madigan, A.L.; Aquilino, S.A. Correspondence between maternal and paternal parenting styles in early childhood. Early Child Res. Q. 2005, 20, 1-12. [CrossRef]

37. Thompson, A.; Hollis, C.; Dagger, D.R. Authoritarian parenting attitudes as a risk for conduct problems: Results from a British national cohort study. Eur. Child Adolesc. Psychiatry 2003, 12, 84-91. [CrossRef] 
38. Loeber, R.; Green, S.M.; Lahey, B.B.; Frick, P.J.; McBurnett, K. Findings on disruptive behavior disorders from the first decade of the Developmental Trends Study. Clin. Child Fam. Psychol. Rev. 2000, 3, 37-60. [CrossRef] [PubMed]

39. Pettit, G.S.; Bates, J.E.; Dodge, K.A. Supportive parenting, ecological context, and children's adjustment: A seven-year longitudinal study. Child Dev. 1997, 68, 908-923. [CrossRef] [PubMed]

40. Zeller, M.H.; Modi, A.C. Psychosocial factors related to obesity in children and adolescents. In Handbook of Childhood and Adolescent Obesity; Jelalian, E., Steele, R., Eds.; Springer: New York, NY, USA, 2008; pp. $25-42$.

41. Berzonsky, M.D. Identity style, parental authority, and identity commitment. J. Youth Adolesc. 2004, 33, 213-220. [CrossRef]

42. Ramsey, A.; Watson, P.J.; Biderman, M.D.; Reeves, A.L. Self-reported narcissism and perceived parental permissiveness and authoritarianism. J. Genet. Psychol. 1996, 157, 227-238. [CrossRef]

43. Chang, L.; Swartz, D.; Dodge, K.A.; McBride-Chang, C. Harsh parenting in relation to child emotion regulation and aggression. J. Fam. Psychol. 2003, 17, 598-606. [CrossRef]

44. Fernandez, E. Children's wellbeing in care: Evidence from a longitudinal study of outcomes. Child Youth Serv. Rev. 2009, 31, 1092-1100. [CrossRef]

45. Flouri, E.; Midouhas, E. Environmental adversity and children's early trajectories of problem behavior: The role of harsh parental discipline. J. Fam. Psychol. 2017, 31, 234-243. [CrossRef] [PubMed]

46. Healy, K.L.; Sanders, M.R.; Iyer, A. Facilitative parenting and children's social, emotional and behavioral adjustment. J. Child Fam. Stud. 2015, 24, 1762-1779. [CrossRef]

47. Teicher, M.H.; Samson, J.A.; Polcari, A.; McGreenery, C.E. Sticks, stones, and hurtful words: Relative effects of various forms of childhood maltreatment. Am. J. Psychiatry 2006, 163, 993-1000. [CrossRef] [PubMed]

48. Vanderfaeillie, J.; Van Holen, F.; Vanschoonlandt, F.; Robberechts, M.; Stroobants, T. Children placed in long-term family foster care: A longitudinal study into the development of problem behaviour and associated factors. Child Youth Serv. Rev. 2013, 35, 587-593. [CrossRef]

49. Williams, L.R.; Degnan, K.A.; Perez-Edgar, K.E.; Henderson, H.A.; Rubin, K.H.; Pine, D.S. Impact of behavioral inhibition and parenting style on internalizing and externalizing problems from early childhood through adolescence. J. Abnorm. Child Psychol. 2009, 37, 1063-1075. [CrossRef] [PubMed]

50. Bongers, I.L.; Koot, H.M.; van der Ende, J.; Verhulst, F.C. The normative development of child and adolescent problem behavior. J. Abnorm. Psychol. 2003, 112, 179-192. [CrossRef] [PubMed]

51. Bongers, I.L.; Koot, H.M.; van der Ende, J.; Verhulst, F.C. Developmental trajectories of externalizing behaviors in childhood and adolescence. Child Dev. 2004, 75, 1523-1537. [CrossRef]

52. Rose, A.J.; Rudolph, K.D. A review of sex differences in peer relationship processes: Potential trade-offs for the emotional and behavioral development of girls and boys. Psychol. Bull. 2006, 132, 98-131. [CrossRef]

53. Rothbaum, F.; Weisz, J.R. Parental caregiving and child externalizing behaviors in nonclinical samples: A meta-analysis. Psychol. Bull. 1994, 116, 55-74. [CrossRef]

54. Pettit, G.S.; Laird, R.D.; Dodge, K.A.; Bates, J.E.; Criss, M.M. Antecedents and behavior-problem outcomes of parental monitoring and psychological control in early adolescence. Child Dev. 2001, 72, 583-598. [CrossRef]

55. Kapungu, C.T.; Holmbeck, G.N.; Paikoff, R.L. Longitudinal association between parenting practices and early sexual risk behaviors among urban African American adolescents: The moderating role of gender. J. Youth Adolesc. 2006, 35, 783-794. [CrossRef]

56. Uji, M.; Sakamoto, A.; Adachi, K.; Kitamura, T. The impact of authoritative, authoritarian, and permissive parenting styles on children's later mental health in japan: Focusing on parent and child gender. J. Child Fam. Stud. 2014, 23, 293. [CrossRef]

57. Chen, X.; Dong, Q.; Zhou, H. Authoritative and authoritarian parenting practices and social and school performance in Chinese children. Int. J. Behav. Dev. 1997, 21, 855-873. [CrossRef]

58. Liu, J.; Xiao, B.; Hipson, W.E.; Coplan, R.J.; Yang, P.; Cheah, C.S.L. Self-regulation, learning problems, and maternal authoritarian parenting in Chinese children: A developmental cascades model. J. Child Fam. Stud. 2018, 1-11. [CrossRef]

59. Power, T.G.; Kobayashi-Winata, H.; Kelley, M.L. Childrearing patterns in japan and the united states: A cluster analytic study. Int. J. Behav. Dev. 1992, 15, 185-205. [CrossRef]

60. Porter, C.L.; Hart, C.H.; Yang, C.; Robinson, C.C.; Olsen, S.F.; Zeng, Q.; Olsen, J.A.; Jin, S. A comparative study of child temperament and parenting in Beijing, China and the western United States. Int. J. Behav. Dev. 2005, 29, 541-551. [CrossRef] 
61. Azuma, H. Education and Socialization in Japan: A Comparison Between Japan and the United States; University of Tokyo Press: Tokyo, Japan, 1994.

62. Chao, R.K. Beyond parental control and authoritarian parenting style: Understanding Chinese parenting through the cultural notion of training. Child Dev. 1994, 65, 1111-1119. [CrossRef] [PubMed]

63. Arnold, D.S.; O'Leary, S.G.; Wolff, L.S.; Acker, M.M. The parenting scale: A measure of dysfunctional parenting in discipline situations. Psychol. Assess. 1993, 5, 137-144. [CrossRef]

64. Itani, T. The Japanese version of the parenting scale: Factor structure and psychometric properties. Shinrigaku Kenkyu 2010, 81, 446-452. [CrossRef]

65. Goodman, R. The Strengths and Difficulties Questionnaire: A research note. J. Child Psychol. Psychiatry 1997, 38, 581-586. [CrossRef]

66. Matsuishi, T.; Nagano, M.; Araki, Y.; Tanaka, Y.; Iwasaki, M.; Yamashita, Y.; Nagamitsu, S. Scale properties of the Japanese version of the Strengths and Difficulties Questionnaire (SDQ): A study of infant and school children in community samples. Brain Dev. 2008, 30, 410-415. [CrossRef] [PubMed]

67. Goodman, A.; Lamping, D.L.; Ploubidis, G.B. When to use broader internalising and externalising subscales instead of the hypothesised five subscales on the Strengths and Difficulties Questionnaire (SDQ): Data from British parents, teachers and children. J. Abnorm. Child Psychol. 2010, 38, 1179-1191. [CrossRef]

68. Ministry of Health, Labor, and Welfare. Summary Report of Comprehensive Survey of Living Conditions 2011. 2011. Available online: www.mhlw.go.jp/english/database/db-hss/dl/report_gaikyo_2011.pdf (accessed on 20 December 2018).

69. Dodge, K. Mediation, moderation, and mechanisms in how parenting affects children's aggressive behavior. In Parenting and the Child's World: Influences on Academic, Intellectual, and Social-Emotional Development; Monographs in Parenting Series; Borkowski, J.G., Ramey, S.L., Bristol-Power, M., Eds.; Lawrence Erlbaum Associates Inc.: Mahwah, NJ, USA, 2002; pp. 215-229.

70. Eddy, J.M.; Leve, L.D.; Fagot, B.I. Coercive family processes: A replication and extension of Patterson's Coercion Model. Aggress. Behav. 2001, 27, 14-25. [CrossRef]

71. Pereira, A.I.; Canavarro, C.; Cardoso, M.F.; Mendonça, D. Patterns of parental rearing styles and child behaviour problems among Portuguese school-aged children. J. Child Fam. Stud. 2009, 18, 454-464. [CrossRef]

72. Heller, T.; Baker, B.; Henker, B.; Hinshaw, S. Externalizing behavior and cognitive functioning from preschool to first grade: Stability and predictors. J. Clin. Child Psychol. 1996, 25, 376-387. [CrossRef]

73. Pinquart, M. Associations of parenting dimensions and styles with externalizing problems of children and adolescents: An updated meta-analysis. Dev. Psychol. 2017, 53, 873-932. [CrossRef] [PubMed]

74. Campbell, S.B.; Shaw, D.S.; Gilliom, M. Early externalising behaviour problems: Toddlers and preschoolers at risk for later maladjustment. Dev. Psychopathol. 2000, 12, 467-488. [CrossRef] [PubMed]

75. Frick, P.J.; Morris, A.S. Temperament and developmental pathways to severe conduct problems. J. Clin. Child Adolesc. Psychol. 2004, 33, 54-68. [CrossRef]

76. Mesman, J.; Koot, H.M. Early preschool predictor of preadolescent internalizing and externalizing DSM-IV diagnoses. J. Am. Acad. Child Adolesc. Psychiatry 2001, 40, 1029-1036. [CrossRef] [PubMed]

77. Prior, M.; Smart, D.; Sanson, A.; Pedlow, R.; Oberklaid, F. Transient versus stable behavior problems in a normative sample: Infancy to school age. J. Pediatr. Psychol. 1992, 17, 423-443. [CrossRef]

78. Shaw, D.S.; Owens, E.B.; Vondra, J.I.; Keenan, K.; Winslow, E.B. Early risk factors and pathways in the development of early disruptive behavior problems. Dev. Psychopathol. 1996, 8, 679-699. [CrossRef]

79. Hosokawa, R.; Katsura, T. Effect of socioeconomic status on behavioral problems from preschool to early elementary school—A Japanese longitudinal study. PLoS ONE 2018, 13, e0197961. [CrossRef] [PubMed]

80. Browne, D.T.; Odueyungbo, A.; Thabane, L.; Bryne, C.; Smart, L.A. Parenting-by-gender interactions in child psychopathology: Attempting to address inconsistencies with a Canadian nation database. Child Adolesc. Psychiatry Ment. Health 2010, 4, 5. [CrossRef] [PubMed]

81. McKee, L.G.; Roland, E.; Coffelt, N.; Olson, A.L.; Forehand, R.; Massari, C. Harsh discipline and child problem behaviors: The roles of positive parenting and gender. J. Fam. Viol 2007, 22, 187-196. [CrossRef]

82. Dekovic, M.; Janssens, J.M.A.M. Parents' child rearing style and child's sociometric status. Dev. Psychol. 1992, 28, 925-932. [CrossRef]

83. Gray, M.R.; Steinberg, L. Unpacking authoritative parenting: Reassessing a multidimensional construct. J. Marriage Fam. 1999, 61, 574-587. [CrossRef] 
84. Eisenberg, N.; Murphy, B. Parenting and children's moral development. In Handbook of Parenting: Vol. 4. Applied and Practical Parenting; Bornstein, M.H., Ed.; Lawrence Erlbaum Associates Inc.: Mahwah, NJ, USA, 1995; pp. 227-258.

85. Weiss, B.; Dodge, K.A.; Bates, J.E.; Pettit, G.S. Some consequences of early harsh discipline: Child aggression and maladaptive social information processing style. Child Dev. 1992, 63, 1321-1335. [CrossRef] [PubMed]

86. Gershoff, E.T. Corporal punishment by parents and associated child behaviors and experiences: A meta-analytic and theoretical review. Psychol. Bull. 2002, 128, 539-579. [CrossRef] [PubMed]

87. Rodgers, D.B. Supporting autonomy in young children. Research in review. Young Child 1998, 53, 75-80.

88. Stormshak, E.A.; Bierman, K.L.; McMahon, R.J.; Lengua, L.J. Parenting practices and child disruptive behavior problems in early elementary school. J. Clin. Child Psychol. 2000, 29, 17-29. [CrossRef]

89. Hart, C.H.; DeWolf, D.M.; Wozniak, P.; Burts, D.C. Maternal and paternal disciplinary styles: Relations with preschoolers' playground behavioral orientations and peer status. Child Dev. 1992, 63, 879-892. [CrossRef] [PubMed]

90. McMahon, R.J.; Forehand, R. Helping the Noncompliant Child: Family-Based Treatment for Oppositional Behavior, 2nd ed.; Guilford: New York, NY, USA, 2003.

91. Patterson, G.R. Interventions for boys with conduct problems: Multiple settings, treatments and criteria. J. Consult. Clin. Psychol. 1974, 42, 471-481. [CrossRef] [PubMed]

92. Else-Quest, N.M.; Hyde, J.S.; Goldsmith, H.H.; Van Hulle, C.A. Gender differences in temperament: A meta-analysis. Psychol. Bull. 2006, 132, 33-72. [CrossRef] [PubMed]

93. Matthews, J.S.; Ponitz, C.C.; Morrison, F.J. Early gender differences in self-regulation and academic achievement. J. Educ. Psychol. 2009, 101, 689-704. [CrossRef]

94. Conrade, G.; Ho, R. Differential parenting styles for fathers and mothers: Differential treatment for sons and daughters. Aust. J. Psychol. 2001, 53, 29-35. [CrossRef]

95. McGillicuddy-De Lisi, A.V.; De Lisi, R. Perceptions of family relations when mothers and fathers are depicted with different parenting styles. J. Genet. Psychol. 2007, 168, 425-442. [CrossRef]

96. Bridgett, D.J.; Gartstein, M.A.; Putnam, S.P.; McKay, T.; Iddins, E.; Robertson, C.; Ramsay, K.; Rittmueller, A. Maternal and contextual influences and the effect of temperament development during infancy on parenting in toddlerhood. Infant Behav. Dev. 2009, 32, 103-116. [CrossRef] [PubMed]

97. Eisenberg, N.; Fabes, R.A.; Shepard, S.A.; Guthrie, I.K.; Murphy, B.C.; Reiser, M. Parental reactions to children's negative emotions: Longitudinal relations to quality of children's social functioning. Child Dev. 1999, 70, 513-534. [CrossRef] [PubMed]

98. Rothbart, M.K.; Bates, J.E. Temperament. In Handbook of Child Psychology Vol. 3: Social, Emotional, and Personality Development; Eisenberg, N., Damon, W., Lerner, R.M., Eds.; Wiley: New York, NY, USA, 2006; pp. 99-166.

99. Ganiban, J.M.; Ulbricht, J.; Saudino, K.J.; Reiss, D.; Neiderhiser, J.M. Understanding child-based effects on parenting: Temperament as a moderator of genetic and environmental contributions to parenting. Dev. Psychol. 2011, 47, 676-692. [CrossRef] [PubMed]

100. McKinney, C.; Renk, K. Differential parenting between mothers and fathers: Implications for late adolescents. J. Fam. Issues 2008, 29, 806-827. [CrossRef]

101. Videon, T.M. Parent-child relations and children's psychological well-being: Do dads matter? J. Fam. Issues 2005, 26, 55-78. [CrossRef]

(C) 2018 by the authors. Licensee MDPI, Basel, Switzerland. This article is an open access article distributed under the terms and conditions of the Creative Commons Attribution (CC BY) license (http:/ / creativecommons.org/licenses/by/4.0/). 